\title{
EL VIAJE POR IRÁN DE GARCÍA DE SILVA Y FIGUEROA. UN RECORRIDO TOPOGRÁFICO Y CARTOGRÁFICO
}

\author{
Fernando Escribano Martín \\ (Universidad Autónoma de Madrid)
}

\begin{abstract}
RESUMEN
Los Comentarios de don García de Silva y Figueroa, terminados en 1624, al final de una embajada que envió Felipe III de Castilla al sah Abbas I de Persia con distintos propósitos, se pueden leer desde distintas ópticas. En esta comunicación vamos a ubicar y contextualizar la embajada en su tiempo y en las relaciones Europa-Persia que se estaban produciendo y eran muy intensas. Pretendemos también hacer un repaso a la producción literaria que se produjo como consecuencia de estos viajes y realizaremos una revisión global de la cartografia del tiempo y del lugar.

En este marco, vamos a recorrer la descripción del país de Persia que hizo don García en su libro $V$, la de aquellos territorios que no había recorrido en sus viajes por el país, a veces siguiendo o en busca del sah, para entender qué fuentes manejaba, cómo las interpretaba, estudiar su método de trabajo y analizar qué información aporta. Es este un estudio parcial, casi una cata, que nos permite comprender mejor la labor del embajador, al tiempo que seguir trabajando en el análisis de todo lo que aportaron sus Comentarios, una obra, que como se dirá en esta comunicación, supuso una aventura en sí misma.
\end{abstract}

\section{PALABRAS CLAVE}

García de Silva y Figueroa, Persia, Irán, Monarquía hispánica, siglo XVII

\section{SYNOPSIS}

The Commentaries of Don Garcia de Silva y Figueroa, completed in 1624, at the end of an embassy sent by Philip III of Castile to Shah Abbas I of Persia with different purposes, can be read with different perspectives. In this communication we want to locate and contextualize the Embassy in its time and in the Europe-Persia relations that were taking place and were very intense. We also intend to review the literary production that was produced as a result of these trips and we will carry out a global review of the cartography of time and place. In this framework, we are going to go through the description of the country of Persia that Don Garcia made in his book V, that of those territories that he had not traveled in his travels through the country, sometimes following or in search of the shah, to understand what sources he handled, how he interpreted them, study his working method and analyze what information he provides. This is a partial study, almost a tasting, which allows us to better understand the work of the ambassador, while continuing to work on the analysis of everything that his Commentaries contributed, a work that, as will be said in this communication, was an adventure in itself.

\section{KEY WORDS}

García de Silva y Figueroa, Persia, Iran, Spanish Monarchy, XVII Century

\section{La aventura de don García en Persia}

Durante el siglo XVII se produjo un número importante, incluso sorprendente, de embajadas entre las cortes europeas y la persa del sah Abbas I. Este trasiego diplomático tuvo sin duda razones precisas y quizá impulsores principales o primigenios (la participación y la 
iniciativa de Anthony Sherley en la primera embajada enviada por el sah Abbas I a las cortes europeas se da como un axioma desde la bibliografía occidental), pero hay todo un mundo alrededor y unos antecedentes que hay que analizar y tener en cuenta para comprenderlo.

La embajada que nos ocupa sobre todo en esta comunicación es la de don García de Silva y Figueroa, que entre 1614 y 1624 dirigió una legación de parte del rey castellano Felipe III al sah Abbas I de Persia. Como tal, y teniendo en cuenta la lentitud de la maquinaria administrativa, fue la última gran embajada oficial de parte española, llegó ya tarde para sus objetivos políticos (un ataque al Turco orquestado desde los dos extremos), el sah persa pensaba en otros aliados y no buscaba ya el enfrentamiento con la Sublime Puerta, el protagonismo de la Monarquía hispánica en estas Indias estaba ya en clara decadencia, y otros protagonistas comerciales europeos se estaban posicionando ${ }^{1}$.

Algunas de las embajadas que se dieron entre la Monarquía hispánica y el sah de Persia se plasmaron en numerosos textos que podían tener una intención u otra, y es también muy significativo el auge de publicaciones sobre Irán que se dio unas décadas después en Europa, sobre todo en Francia, en Inglaterra y en la Monarquía hispánica sobre Persia.

De la embajada de don García de Silva y Figueroa² salieron unos Comentarios escritos de la mano del embajador, aunque fuese en tercera persona. Estos comentarios se empezaron a escribir nada más salir de Lisboa y acabaron prácticamente con la muerte del embajador en alta mar, ya cerca de casa. Si los propios Comentarios eran parte del objeto de la misión, o fue iniciativa del narrador, nada sabemos, pero sí podemos reconstruir la aventura de su edición. Parece lógico fechar el manuscrito en 1624, que es cuando sabemos que el embajador muere y concluye su redacción. No sabemos qué sucede con el manuscrito, aunque sí que se realizan dos copias parciales, sin los dos primeros libros, la noticia de una de las cuales, la que se encuentra en el British Museum, ha surgido hace pocos años ${ }^{3}$. El manuscrito original y una de sus copias están custodiadas en la Biblioteca Nacional de Madrid. El manuscrito y su importancia debían ser conocidos por un público interesado, y sabemos que la primera edición del texto, parcial, correspondiente a una de las copias (¿a cuál?) en las que faltan los dos primeros libros, se realizó en francés, en París, por Mr. de Wicqfort ${ }^{4}$, en 1667. La parte referida a la Vida de Tamorlán, en el libro V, se incluyó en la edición de E. Llaguno de la embajada de Ruy González de Clavijo, en $1782^{5}$. No hay más noticias del texto hasta que Pascual de Gayangos dice haberlo rescatado de una librería de viejo y pocos años después, en 1903 y 1905, es publicado en dos tomos por la Sociedad de Bibliófilos Españoles, bajo la dirección de Manuel Serrano y Sanz. Esta es la primera vez que el texto se publica de forma completa, y en español. La siguiente edición que señalamos por su relevancia es la muy cuidada y acompañada de un importante aparato científico, realizada bajo la dirección

\footnotetext{
${ }^{1}$ La irrupción del comercio inglés, no solo en el asunto de la seda que tanto preocupaba a Robert Sherley como negocio personal, está claro en el texto de don García. En el texto también se muestra y explica cómo al sah ya no le interesaba el tema del ataque contra el Turco, sí la recuperación de territorios que entendía persas, y como ingleses y holandeses estaban ya en su órbita de negocio. Con don García, él lo muestra en el texto, se intenta jugar en estas negociaciones, y desde parte hispana da la impresión de que se le está haciendo luz de gas.

${ }^{2}$ J. M . Córdoba ha tratado distintos aspectos de esta embajada, ver, por ejemplo: Córdoba 2005, 2006 y 2016.

${ }^{3}$ Tomo II, edición 2011: Joan-Pau Rubiés, "Nota sobre un Tercer Manuscrito de los Comentarios", pp. xi-xiii. Este tercer manuscrito se encuentra en la British Library, Ms Sloane 2846.

${ }^{4}$ L'ambassade de Garcias de Silva Figveroa en Perse, contenant la politiqve de ce grand empire, les moeurs du Roy Schach Abbas, \& vne Relation exacte de tous les lieux de Perse \& des Indes, oú cét Ambassadeur a esté, traduite de l'Espagnol pat Monsieur De Wicqfort, Paris, Jean Dvpuis, 1767.

${ }^{5}$ «Noticias del Gran Tamurlan sacadas del libro V de los comentarios mss. de don Garcia de Silvą» en Historia del Gran Tamorlán y enarración del Viage, y relación de la embaxada que Ruy González de Clavijo le hizo por mandado del muy poderoso señor Henrique el Tercero de Castilla, ed. por E. Llaguno y Amirola, Madrid.
} 
del profesor Laureiro, en 2011, del Centro de História de Além-Mar (Universidades Nova de Lisboa y Dos Açores) y que es objeto de otro artículo en este mismo volumen. Y ha habido también otra edición posterior, en inglés, en 2017, llevada a cabo por Turley y Souza.

En esta breve historia de la edición de los Comentarios de don García viene implícita la explicación del poco conocimiento que se tiene sobre el texto. Cuando los orientalistas buscamos a nuestros predecesores, se suele hablar, entre otros, del viaje de Pietro della Valle por Irán y Oriente, y es correcto hacerlo, pero no se dice nada, o se menciona por encima, el viaje de don García y del texto que emanó de la misión diplomática ${ }^{6}$. Nos puede parecer injusto su general desconocimiento, y sin duda lo es, a tenor de la importancia del escrito y de las aportaciones que presenta, pero es entonces cuando hay que recordar que se publicó primero solo una parte del texto, traducido, en el marco de toda una serie de escritos de viajes a Persia (que solo conocería un público muy especializado), unas décadas después de la realización del viaje. Ya no se volvería a publicar hasta 1903, de mano de unos pocos bibliófilos, que recuperaban textos antiguos como éste y que permitió ampliar su conocimiento de nuevo en un ámbito muy restringido. Solo en nuestros tiempos, la comunidad científica internacional empieza a saber de su existencia de forma general, a apreciarlo, gracias a una edición científica con todas las garantías, a su traducción al inglés y a toda una serie de publicaciones que pretenden presentar, estudiar y valorar el texto en su justa medida. El rescate que realizó Wicqfort en 1667 y la valiente y a veces oscurecida misión de la Sociedad de Bibliófilos Españoles, empiezan ahora a obtener sus frutos.

Veamos ahora, siquiera someramente, cuál fue y a qué se debió ese intercambio diplomático que se dio entre Persia e Irán en el siglo XVII, algunos de los textos y mapas que de ahí surgieron, y cómo se desarrolló la embajada de don García.

\section{Cartografía e itinerarios de Persia anteriores y contemporáneos al siglo XVII}

Independientemente de que García de Silva llevase consigo o no, a lo largo de su viaje por Persia, un mapa, se antoja inequívoco que debía conocer alguno de los que hasta entonces se habían publicado. La elaboración de mapas era ya algo habitual en su tiempo y, si bien es una especulación, se podría pensar que, si su texto se hubiese editado al regreso del viaje, bien se hubiese podido mostrar su itinerario en forma de mapa, si no estaba trabajando para ello, lo mismo que se hizo con el texto de Pietro della Valle ${ }^{7}$ o con los de otros viajeros contemporáneos.

De hecho, en el manuscrito de don García se incluye un mapa de Goa que también podría atribuirse a Manuel Godinho de Heredia, fechable por lo tanto en 1616, que es cuando ambos coinciden en la ciudad, y que Fernando Marías señala como el, posiblemente, más antiguo levantamiento cartográfico de calidad de la isla de Goa y de su entorno (Marías, 2002: 140).

Un mapa es una representación geográfica de la Tierra o de parte de ella en una superficie plana (Diccionario de la $\mathrm{RAE}^{8}$ ), es por lo tanto una buena muestra del conocimiento geográfico contemporáneo a su publicación, o de lo que se pretende mostrar en cada tiempo. Es a partir del viaje de Colón ${ }^{9}$ y posteriormente del de Magallanes, cuando se tiene conciencia del orbe

\footnotetext{
${ }^{6}$ Un simple ejemplo de una realidad ampliamente conocida. En el texto de Rudi Matthee (2012) sobre el Irán safávida a través de los ojos de los viajeros europeos, sí cita (p.11) a García de Silva como uno de esos viajeros, pero no es uno de con los que trabaja o desarrolla. Y este autor al menos le conoce.

${ }^{7}$ Carte pour le voiage de Levant de Pietro della Vallé, depuis Venise jusqu'à Bagdaht, par Constantinople, le Caire, Jerusalem et Alep.

${ }^{8} \mathrm{https}$ ://dle.rae.es/mapa, consultado el 13/08/2020.

${ }^{9}$ El mapa de Juan de la Cosa, de 1500, conservado en el Museo Naval de Madrid, es un buen ejemplo. Seguramente se realizó para mostrar a la Corona los descubrimientos realizados en América desde su descubrimiento. Tiene origen en una carta náutica, y es el primer mapa que muestra América.
} 
como conjunto, pero ya previamente se intentaba reflejar la Tierra conocida, lo que se conocía de verdad y lo que se imaginaba.

Aquí vamos a señalar y referenciar una serie de mapas que dan muestra del saber cartográfico al que se podría tener acceso en la época, con todas las limitaciones a la comunicación u ocultaciones de que podían ser objeto. Hoy, acostumbrados a la accesibilidad de la red, o la disponibilidad de pedir libros por préstamo interbibliotecario, nos cuesta imaginar un mapa o un libro como un tesoro inaccesible, por decisión o por problemas prácticos de acceso, pero durante mucho tiempo el saber y sus instrumentos estaban en manos de unos pocos, y bajo la máxima de que saber es poder, muchos eran fieles guardianes de su parcela de conocimiento.

Desde una perspectiva opuesta a la que acabamos de señalar, parece interesante reseñar viajes contemporáneos al de don García de los que emanaron un texto que lo narraba. El conocimiento sobre Persia desde Europa, con todas estas herramientas de descripción que se iban acumulando, era cada vez mayor en el siglo XVII. Independientemente de estas fuentes, la referencia seguían siendo los antiguos, el saber del que se tenía conocimiento, la base cultural de Occidente, además de que las publicaciones contemporáneas, cartográficas o textuales, no eran de general acceso.

Veamos ahora cuáles eran algunas de las referencias cartográficas que existían en la época de la embajada de don García o que le fueron contemporáneas, y haremos también un repaso por algunos de los textos que surgieron de otras embajadas con destino u origen Persia. El mejor modo de comprender y apreciar en su magnitud un texto es contextualizarlo y compararlo con obras contemporáneas, si es que existen. Veremos cómo, alrededor de los Comentarios de don García, existieron también varias obras contemporáneas que sin duda permitieron conocer mejor la historia, la realidad contemporánea y la geografía de Persia a los europeos.

El Atlas catalán de 1375, realizado por la familia Cresques de Palma de Mallorca, fue un regalo para la biblioteca de Carlos V de Francia y hoy se conserva en la Biblioteca Nacional de Francia ${ }^{10}$. Es un mapamundi que parte de cartas náuticas, y que muestra el territorio conocido e incluso imaginado a partir de fuentes árabes y occidentales, incluyendo entre sus referencias, por ejemplo, trabajos como el de Marco Polo.

La edición de Gioacomo Gastaldi de la Geografía de Ptolomeo, fechada en 1548, en Venecia, reunió una serie de mapas realizados por él hasta entonces, y que daban una visión global del orbe conocido (incluía también dos planiferios). Su Persia Nova Tabula se puede considerar el primer mapa moderno cuyo título incluye el nombre de Persia (Biedermann 2011, tomo II: 371).

Del mismo modo, el mapa de John Speed (1552-1629): The Kingdome of Persia with the cheef Cities and Habities Described, publicado en Londres en 1631, es otro ejemplo del conocimiento cartográfico que se tenía entonces sobre la región, fuesen manejados o no por los viajeros que la atravesaban. O el de Nicolas Sanson d'Abbeville (1600-1667), L'Empire du sophy des Perses, publicado en París en 1652, donde el país aparece organizado en regiones.

Es obvio que a partir de unos primeros pasos más o menos inciertos en la representación cartográfica, donde se reflejaba tanto lo conocido como lo interpretado, sin desdeñar lo imaginado, la calidad y la exactitud cada vez son mayores, y estos últimos ejemplos, o los posteriores de Nicolas Witsen (1641-1717): Asia Accuratissime descripta (de aproximadamente 1700) o el Imperii Persici delineatio ex scriptis potissimum geographicis

\footnotetext{
${ }^{10}$ En este enlace de la Biblioteca Nacional de Francia se puede estudiar el Atlas: https:/gallica.bnf.fr/ark:/12148/ btv1b55002481n/f14.zoom.r=cresques.langEN
} 
Arabum et Persarum, de Adrian Reland, publicado en Amsterdam en 1705, muestran un avance en la técnica cartográfica y en el conocimiento de la región.

No todos los itinerarios que se realizaron por la región tuvieron su plasmación en un mapa, como sí lo tuvo el viaje del patricio romano Pietro della Valle ${ }^{11}$. El recorrido (16121624) que tuvo inicio en un peregrinaje a Jerusalén, le terminó llevando a la India. Della Valle fue enviando cartas a un amigo con la idea de describir Oriente y publicar un libro sobre su viaje. Estas epístolas (que su amigo debía convertir en un libro) al final fueron recopiladas por el peregrino, y constituyen un estupendo relato y descripción del mundo que visitó. Fue publicado y ampliamente conocido, y por lo tanto su testimonio se toma como referencia en los orígenes del Orientalismo. Por cierto, coincidió con de Silva en Isfahán, y ninguno de los dos habló bien del otro (sobre este encuentro, que no es solo una anécdota, han escrito Córdoba Zoilo 2016, Brancaforte 2011 e Invernizzi 2011).

Viajes entre Irán en Europa en este tiempo hubo muchos, pero solo los que dejaron un texto como resultado, o fueron referenciados por su importancia, son los que conocemos. Entre los que se publicaron, y en esta época se editaron bastantes, unos tuvieron más trascendencia que otros. El de Pietro della Valle fue ampliamente conocido, incluso en su tiempo. Y de hecho, ahí están los distintos mapas publicados sobre su viaje, con distintos recorridos, algunos de los cuales hemos ido señalando.

Hubo viajes, sin embargo, de los que salieron varios textos. En 1627 se produjo la primera embajada oficial británica hacia el sah Abbas I de Persia, la comandaba Dodmore Cotton. Le acompañaban Robert Sherley y Naqd Alí Beg, uno y otro se decían embajadores del sah y el rey Carlos I les envió de vuelta a Persia para que aclarasen la situación. Ambos pretendían terminar de arreglar el asunto del comercio de seda que aparece tratado en el texto de García de Silva. En el viaje de regreso, a la altura de la India, el persa se suicidó, y en el de vuelta a Inglaterra murieron Sherley y Cotton. Aparte de este trágico final, hubo dos textos que se publicaron a partir del viaje por dos de los miembros de la comitiva, el de Thomas Herbert's A relation of some yeares travaile.. Into Afrique and the greater Asia, especially the Territories of the Persian Monarchie, que tuvo además éxito de ventas, y The journal of Robert Stodart; being an account of his experiences as a member of Sir Dodmore Cotton's mission in Persia in 1628-29, que ni siquiera se publicó y fue recuperado por Edward Denison Roos en 1935.

Esta embajada y los dos textos que emanan de ella, independientemente de que fuesen más o menos conocidos, responden a una larga tradición de viajes a Persia y Oriente desde tierras europeas. Ludovico de Varthema (Bolonia, ca. 1470-1517) hizo un recorrido entre 1502 y 1508 que le llevó a la Meca, donde describió los ritos del peregrinaje (es seguramente el primer testimonio europeo al respecto), viajó a Persia en 1504, llegó a la India, Ceilán, Sumatra, Borneo y regreso siguiendo la ruta portuguesa. En 1510 publicó en forma de crónica un texto sobre su viaje: Itinerario de Ludouico de Varthema Bolognese ${ }^{12}$, que es una referencia para muchos viajeros ${ }^{13}$ posteriores a Oriente. Existe toda una serie de textos muy interesantes del siglo XVI que hablan de estos contactos entre Persia y Europa, y que aquí

\footnotetext{
${ }^{11}$ Además del mapa señalado previamente, véase, en el catálogo de la Bibliotheque Nationale de Françe (https://data.bnf.fr/fr/12066709/pietro_della_valle/, consultado el 1/09/2020): Itinéraire de Perse de Bagdaht à Ispaham et d'Ispaham à Ferhabad... selon la relation de Pietro della Vallé. Tirée des Cartes pour les Itinéraires et voyages modernes... de P. Duval, Paris : Chez l'Autheur, 1677.

${ }^{12}$ Enlace a la Biblioteca Digital Hispánica (Biblioteca Nacional de España), donde está el texto digitalizado: http://bdh-rd.bne.es/viewer.vm?id=0000001056

${ }^{13}$ Richard Francis Burton, The Pilgrimage to Al-Medinah and Meccah, le cita entre sus predecesores, lo mismo que también señala a Alí Bey (Domingo Badía) como otro europeo que, disfrazado, entró en La Meca, y que de hecho fue su gran referencia.
} 
vamos poco menos que a enumerar, como la Conquista de las Indias de Persia e Arabia que fizo la armada del rey don Manuel de Portugal e de las muchas tierras, diversas gentes, extrañas riquezas y grandes batallas que allá hubo. En sumario del bachiller Juan Agüero de Trasmiera, de 1512 (ed. de Luis Gil); o el tratado de Fernando (o Hernando) Colón, que por cierto había sido propietario del libro anterior (ed. de Luis Gil, 1999, p. 28): Discurso declaratorio del derecho que la corona tiene en la conquista de Persia; o la Relazione di Persia (1542) de Michel Membré, editada bastante tiempo después (1969) como manuscrito inédito del Archivio di Stato di Venezia por Giorgio Raimondo Cardona y Francesco Castro, y en también en inglés, en 1993: Mission to the Lord Sophy of Persia (1539-1542) por A.H. Morton.

En torno al tiempo en el que Anthony y Robert Sherley marchan a Persia (entre 1598 y 1599) y dicen desencadenar ese intercambio de embajadas de la que la de don García es la última, se están produciendo otras por parte de otros países europeos, también involucrados con el conflicto turco-persa, y a los que solemos prestar menos atención (la gran referencia para entender estas embajadas, sobre todo las de parte hispana, es la obra de Luis Gil: El Imperio luso-español y la Persia safávida). Una de estas embajadas europeas sería la de Safer Muratowicz, enviada por Segismundo III Vasa de Polonia al sah Abbas, quizá porque la enviada por el sah a las cortes europeas no pasó por Varsovia porque el zar moscovita Boris Godunov la desvió (Polczynski 2014: 4). De la legación que dice dirigir Anthony Sherley surgen varias descripciones de lo visto y recorrido, como la de la corte del sah de Abel Pinçon, recogida en los textos editados por Lambert \& Morisot (París, 1651). No se descubre un mundo nuevo. Estos contactos tuvieron importantes precedentes y se continuaron después.

Algo posteriores a la embajada que nos ocupa, la de don García, hubo una serie de viajes, sobre todo de parte francesa, que abrieron un más general conocimiento sobre Persia y su mundo. Jean Baptiste Tavernier consiguió una reputación como viajero gracias a sus Seis Viajes, Les Six Voyages de J. B. Tavernier, realizados durante cuarenta años, publicados en dos tomos en París, en 1676. Jean Chardin (1643-1713) obtiene también una importante fama con sus Voyages de Monsieur le Chevalier Chardin en Perse et Autres Lieux de' L'Orient, publicados en 1711 y muchas veces referenciados como fuente de conocimiento contemporánea sobre la región. No hay que olvidar la Relation d'un voyage fait au Levant, escrita por Jean de Thévenot en 1665. Y como postrer ejemplo de relación de viaje a partir de una embajada, se podría señalar el libro de Adam Olearius (1603-1671) escrito a partir de la embajada enviada por Frederick, duque de Holstien al gran duque de Moscú y al rey de Persia.

Si pretendiésemos hacer un rápido repaso a las publicaciones que se hicieron en la Monarquía hispánica a partir de este intercambio diplomático, habría que seguir también el hilo de las embajadas que se fueron sucediendo ${ }^{14}$. Solemos dar por bueno, como ya hemos dicho, el inicio de este intercambio de embajadas entre Europa y Persia a partir de la primera enviada por el sah Abbas I, comandada por Husein Ali Beg y, según testimonio propio, también por Anthony Sherley ${ }^{15}$. Partirían a finales de 1599 y en 1601, en Roma, el papa

\footnotetext{
${ }^{14}$ En el ámbito de la recuperación de la memoria de la presencia española en Oriente hay que señalar el trabajo de J. Ma . Córdoba, con el catálogo de la exposición La aventura española en Oriente [1166-2006], celebrada en el Museo Arqueológico Nacional (2006) y el volumen coordinado de Arbor, Españoles en Oriente Próximo (1166-1926) (2005), entre otros trabajos. De un modo más específico, sobre todo lo que se generó desde un punto de vista editorial, en el siglo XVII, en la Monarquía hispánica, a partir de estas relaciones con Persia, ver Escribano 2017-18.

${ }^{15}$ Sobre Anthony Sherley, y como colofón al trabajo de toda una vida, donde el personaje iba saliendo continuamente en sus investigaciones, ver el libro de Luis Gil 2018, que es la mejor actualización de lo que sabemos sobre el inglés en base, fundamentalmente, a archivos españoles.
} 
separó la embajada por la imposible convivencia entre ambos. Anthony Sherley publicaría una relación de sus viajes por Persia (Sir Anthony Sherley: his Relation of his Travels into Persia, 1613). Hasta tres miembros de la embajada se convirtieron al cristianismo, y uno de ellos, Uruch beig Bayyat, don Juan de Persia, publicaría unas Relaciones donde habla de la historia de Persia y del viaje seguido por la embajada.

Entre esta primera que llegó a las cortes europeas y finalmente a Madrid y la que se podría considerar la última, de algún modo la que constató el fracaso de la intención de la alianza contra el Turco y la demostración de la pérdida de preeminencia de la Monarquía hispánica en la región, la de don García, se produjeron varias embajadas o contactos desde una y otra parte, muchas de las cuales están referenciadas y analizadas en los Comentarios de don García. El papel de Antonio de Gouvea en ellas no siempre está claro, ni a qué intereses responde, pero dejó un par de textos que son también fundamentales para conocer la región, su historia y la política contemporánea.

El último de estos intercambios desde parte hispana, la que debía ser la gran embajada que fuera respuesta a las anteriores enviadas por el sah, cuidadosamente preparada y que también sufrió de la lentitud de la administración española, fue la que se confió a don García de Silva y Figueroa. De esta embajada salieron los Comentarios ya señalados, y que ahora en parte vamos a seguir para incidir en la descripción de Persia que aporta, no tanto a lo largo del recorrido, sino cuando hace un estudio, a partir de fuentes antiguas y contemporáneas, de la parte del país que no habían visitado.

El tiempo trascurrido desde el comienzo de la embajada hasta su final es excesivo, diez años. Esto se debe sobre todo a dilaciones intencionadas por parte de las autoridades portuguesas que quizá no veían bien que fuese un español quien estuviese al mando de la legación, pero que también debían ver con malos ojos a un enviado del rey que ponía en evidencia la dejadez y la corrupción de aquella administración de las Indias. También hubo mala suerte con los vientos y decisiones mal tomadas en viajes que solo se podían hacer en épocas muy concretas. Lo cierto es que don García murió en alta mar, cerca ya de su casa, como quizá siempre había temido. Triste colofón a la triste historia que todavía le quedaba por vivir a su manuscrito.

\section{La descripción ${ }^{16}$ de Persia del libro V}

Al ser Casbin [Qazvin] la última jornada del embajador por las provincias de Persia, hace en este punto de sus Comentarios un resumen de lo que le contaron de los lugares en los que no estuvo, pero sobre todo lo realiza en base a la "lección de la antigüedad, que es lo que da verdadera lumbre y conocimiento de todo lo que se debe saber del Mundo" (Silva 2011: 385). El libro V, bajo los epígrafes de "Noticias de Persia" o "Noticias de Mesopotamia", complementa la descripción de los lugares de Persia por los que no ha pasado en su viaje por el país, los que le quedaban por describir, cerrando así, en su narración, una visión completa del país.

Los Comentarios de don García de Silva y Figueroa van más allá de una descripción del viaje realizado, de los lugares recorridos. Comprende también un informe, muchos, sobre el estado de la Administración de las Indias dirigido al rey, la descripción de distintas ciudades y espacios, estudios sobre la Antigüedad y diversos análisis del presente en el que se desarrolla. Pero también cuenta ese viaje que realizó, y lo hace con un detalle y sensibilidad que siguen encandilando al leerle hoy.

\footnotetext{
${ }^{16}$ En este apartado vamos a seguir en lo posible la narración, la nomenclatura e incluso el estilo del embajador. Aclararemos y anotaremos cuando lo creamos necesario, y señalaremos entre corchetes, cuando sea posible, el nombre actual de la población de la que está hablando. Utilizaremos frecuentemente las palabras de don García, actualizadas para facilitar la lectura.
} 
Así, el libro I es el viaje de Lisboa a Goa; el libro II describe la ciudad de Goa, donde tuvo que pasar mucho tiempo; el libro III es el viaje de Goa a Ormuz vía Mascate; el libro IV narra el viaje de Ormuz a Casbin (Ormuz, Lara, Xiras, Margascan, Persépolis, Spahan y Casbin). En el libro quinto describe todo aquello que no ha visitado previamente en el recorrido citado, en base a fuentes clásicas pero también contemporáneas, contraste más que interesante para conocer el saber heredado y el que se generaba en su tiempo al respecto. Y los libros VI y VII son los de regreso, de Casbin a Goa (1618-1620) y de Goa a Lisboa, larguísimo, cuatro años de viajes, esperas y desesperación (a veces, leer el texto es angustiante, entiendes perfectamente el sentir del embajador) y que dan con la muerte de don García en el mar, pasado ya el cabo de Buena Esperanza, cuando el regreso al hogar se debía sentir ya cercano.

Aquí vamos a hacer un recorrido veloz por esta descripción que nos servirá también para analizar qué fuentes manejaba el embajador, docto sin duda en los textos antiguos, pero que utiliza también otras fuentes de su tiempo, testimonios directos y secundarios sobre las tierras que va recorriendo. Vamos a utilizar su modo de nombrar ciudades y territorios, intentado siempre aclarar, la primera vez que se utilice, cómo los nombramos hoy en día. El embajador hace un esfuerzo de integración de todo tipo de fuentes, de modo que unas y otras se contrastan y complementan. Si bien es cierto que no señala manejar ningún mapa, esta circunstancia no es óbice para que los conociese o incluso utilizase en su viaje. El orden en la exposición de los territorios, cómo sigue o integra itinerarios que describe por escrito, sobre todo cuando realiza una síntesis, parece a veces remitirse a un mapa, estar describiéndolo. Lo mismo que en su texto presenta uno de los mejores planos de Goa elaborados en su época, que llevase una completa biblioteca consigo, que le acompañase o contratase un dibujante que ilustró estatuas y relieves de Persépolis, o que contraponga en su narración la geografía antigua y la moderna, es muy difícil suponer que no manejó mapas o incluso que no estuviese trabajando en la elaboración de uno acerca del territorio recorrido y documentado.

Elabora su narración, como hemos dicho, según geógrafos e historiadores antiguos, sobre todo, y empieza por el "mar Caspio o Hircano, que ahora llaman de Bacu, por su mayor distancia Noroeste Sueste, que es lo mismo que Maestro y Siroco ${ }^{17 ", ~(S i l v a ~ 2011: ~ 385) . ~ " L o s ~}$ historiadores y geógrafos de la antigüedad solo tenían respecto a las distancias terrestres con los nombres de las provincias, montes y ríos que las dividían, y de las ciudades que más notables había en ellas, sin tener respecto a la correspondencia del cielo, ni a sus paralelos y meridianos, por donde se pueda conocer su verdadera situación" (Silva 2011: 386). Él se ve en otro tiempo científico, y resuelve dudas o malos entendidos, como la distancia entre el Mar Caspio y el Seno Pérsico, más extensa de lo esperada, e intenta comprender el clima de la zona en función de la latitud y longitud medida (Silva 2011: 386). También se equivoca, en este punto señala que Xiras [Shiraz] es Çiropolis, y que aquí está el sepulcro de Ciro. Hoy lo sabemos situado en Pasargada.

Entre Xiras y Margascan [Felip Masó 2020, la sitúa en la actual Kinara], cerca de la cual está Persépolis, hay diez leguas, más orientales que Spahan [Isfahan]. Spahan no pertenecía a la Media, sino a la provincia de Persia. A su occidente estaría Susiana (Susien en su tiempo, señala), al norte la Media, a oriente parte del antiguo y gran reino de Parthia (llamado ahora Corassan [Jorasán]), Carmania (hoy, siglo XVII, Cherman) al oriente y al mediodía Carmania la desierta o reino de Lara [Lar, capital de Laristán] (Silva 2011: 386387). En muchas de estas descripciones sigue dando la impresión de que el embajador las

\footnotetext{
${ }_{17}$ Señala los puntos cardinales y sus combinaciones con vientos, pero utiliza casi siempre, y explica, las correspondencias entre los dos modos de señalar una dirección.
} 
está realizando con un mapa delante. Y sobre esta referencia explica el lugar que estudia y los territorios que le están alrededor.

Habla después de geógrafos posteriores y del reino de Bactra (entonces Balca) [Bactriana o Bactria, con capital en Balh / Bactra / Zaraspa] y cómo ha mudado de bactrianos a usbeques, que se han apoderado de los escitas (scithgas) o tártaros nogais, enemigos de los persas. Al norte de este reino estaría el río Abiaomu, entonces Oxo, [estaríamos hablando del Amu Daria ${ }^{18}$ ] que divide la región de los tártaros chacatias, antiguamente los sogodianos, con cabeza en Samarkanda (antes Maracanda), tan engrandecida hace doscientos años por Timur Lag, hoy (entonces) cuatro aldeas (Silva 2011: 387). Divide esta provincia de Sogodia, que incluye otras menores, el río Calima (el Laxarte que Alejandro Magno pasó frente a los escitas, creyendo que era el río Thanais el que divide Asia de Europa). Ambos entran en el Mar Caspio por esta parte, pero el Oxo con mucho más caudal. Este libro V parece un estudio de gabinete. El embajador ha recogido la información sobre la parte del país que no ha recorrido. Integra testimonios, información transferida de forma oral, quizá traducciones que de una forma u otra le son transferidas y su gran referencia, que son los autores clásicos, y con todo ello va completando un puzzle que se entiende perfectamente con un mapa delante. Que lo estuviese construyendo o lo tuviese delante, resta por confirmar.

La costa marítima entre los ríos Abiaomu y Calima es la parte más occidental de la Sogodia, la región de los chacatais, antiguamente llamada Margiana. Según don García, la grandeza de Tamur se transfirió a los usbeques, sus vecinos, unidos a los bactrianos, obedeciendo a un solo rey, con Balca y Bucara como ciudades más importantes, no como los chacatais, divididos entre diferentes señores, y con Samarkanda reducida a una humilde población (Silva 2011: 388).

El reino y provincia de Corassan (la antigua Parthia o Parthiene) es ahora de las más ricas y poderosas de esta monarquía, "siendo notorio engaño de los que la tienen por Aria, pues ésta infaliblemente es provincia de Arat, considerando casi un primer y antiguo nombre, contermina de la primera India, como lo es ahora la provincia de Candar" (Silva 2011: 388).

"Toda la clase de los Historiadores antiguos, que son Justino, Arriano, Diodoro Sículo, Plutarco y Quinto Curçio, concuerdan haber entrado Alejandro a la India desde la provincia de Sogodia, y así se puede presumir que fue por el reino, que hoy se llama de Badajan, conquistando primero aquellos reyes que eran señores de la parte más septentrional della. Y después navegando por el río Hidaspes ${ }^{19}$ y el Indo hiciese guerra a los más australes, hasta llegar al Oçeano, adonde puso fin a su memorable expedición” (Silva 2011: 389). Cita luego el testimonio de soldados y marineros, o el de un capitán de la fortaleza de Tidore en el Maluco, que habrían visto, en la desembocadura del Indo, las aras que dejó Alejandro para conmemorar dicha expedición. Él expone un testimonio contemporáneo que justifica una información vertida por los antiguos, un modo de trabajo y de búsqueda de conocimiento.

También señala cómo desde Samarkanda, Bucara [Bujará] y Balca [Balch, Balj], en el tiempo del embajador de usbeques, cada año va una gran expedición al Catayo, y a su ciudad principal Cabalec, que Marco Polo nombra Canbalu ${ }^{20}$. Y aquí se apoya en el testimonio de jesuitas que allí habían estado para identificar el Catayo con el reino de la China. Y señala

\footnotetext{
${ }^{18}$ El Amu Daria, Oxus en la Antigüedad, desemboca actualmente en el Mar de Aral, aunque previamente lo hacía en el Mar Caspio.

${ }^{19}$ El Jhelum, afluente del Indo.

${ }^{20}$ Kambaluk / Kambalik / Cambaluc: Pekín, Beijing. Actual capital china, fundada por Kublai kan como tal.
} 
también a Haiton Armenio ${ }^{21}$ y a Nicolao, Maftio y Marco Polo ${ }^{22}$, venecianos, como fuentes fiables sobre aquella región. Pasa después a hablar de los mongoles (tártaros) y cómo llegaron hasta Hungría y Silesia (Silva 2011: 391), o de cómo es en Persia, Media, Asiria y Mesopotamia donde se asentaron, especialmente en Sogodia y Batra, donde entonces eran todavía sus señores. Es también muy interesante cómo habla de las embajadas que envió el Sumo Pontífice Inocencio, comandadas por franciscanos y dominicos para conocerlos y entablar relación. Aunque confunda algo China con el imperio mongol, habla de Gengis kan, de cómo están organizados y del origen mongol de varios reinos o reyes de la zona, haciendo alusión a este pasado para Persia y otros vecinos.

Le dedica después un capítulo extenso a la vida de Tamorlán ${ }^{23}$, señalando, ciertamente, el famoso viaje de Ruy González de Clavijo, pero trabajando sobre todo con otras fuentes. Este capítulo del texto de Silva y Figueroa fue incluido en una de las reediciones del texto del viajero madrileño ${ }^{24}$, por orden de Enrique III de Castilla al gran Tamorlán, que de nuevo nos mete en la aventura que es en sí la publicación o conocimiento de estos textos. Este es un ejemplo más de lo que suponen sus Comentarios, es también un estudio histórico de los acontecimientos y personajes que surgieron de los lugares que van atravesando. Y no es una mera referencia o cita, plantea a veces pequeños ensayos que forman parte del texto, pero que pueden ser extraídos y utilizados como se hizo, más de 150 años después de su redacción, en la edición de Llaguno del texto de González de Clavijo.

Después de este capítulo sobre Tamorlán, vuelve de nuevo a la descripción del país que no ha recorrido (Noticias de Persia - continuación, Silva 2011: 417). "Viene desde el viento Nordeste, y boca del rio Oxo, hasta el sur o mediodía, corriendo la sinuosa provincia de Hircania, y abrazando con su torcida costa, la parte del Mar Caspio comprendida en estos rumbos, hasta los confines de la Media. Starabat y Masandaran serían provincias menores de esta, la primera al mando de un gran gobernador, denominado $\mathrm{Chan}^{25}$, por ser frontera con los usbeques, y la segunda, con capital en Farabat, de donde es su madre, a la que la afición del rey le está suponiendo crecer y poblarse. Al occidente de Hircania está la Media, "provincia nobilísima y de grande nombre en los siglos de la antigüedad" (Silva 2011: 420). La parte que sigue es Hircania, abrazando el Mar Caspio, la parte marítima y más septentrional es el reino o provincia de Guilán [Gilan]. De aquí vienen muchos productos, entre ellos la seda, y también de otras provincias, como el embajador va señalando. Guilán tuvo reyes propios, reconocidos por Persia, hasta que el sah Abbas I tomó el reino, procedimiento o hechos que también vienen explicados en el texto.

Señala después la ciudad de Ardeuil [Ardebil, Azerbaiyán, Irán], sacrosanto para los persas por estar aquí los sepulcros del Xeque Aidar y de Hismael Sophi ${ }^{26}$, su hijo. En el

\footnotetext{
${ }^{21}$ Haytón de Armenia o de Córico (moriría alrededor de 1320). Su obra: La Flor des Estoires d'Orient, es una geografía de Asia, y cuenta también la aparición del Imperio mongol.

${ }^{22}$ Aunque aparentemente del todo conocido, el viaje de Marco Polo no siempre fue admitido como el testimonio verídico de un viajero a la zona, ni que todo lo que dice sea cierto. Si bien a partir de un cierto momento desaparecen del texto, hay que recordar que los primeros viajeros a la corte del gran Kan son los hermanos Nicolás y Mateo, y que es en el segundo viaje cuando se incorpora quien después escribirá el texto: Marco, hijo y sobrino de los primeros. Todo, claro, dando por bueno lo que se cuenta en el libro, que es casi la única fuente de verosimilitud de una historia que todos creemos conocer pero que en realidad no se conoce tanto.

${ }^{23}$ Comentarios, vol. 2, liv. 6, cap. 1, pp. 168-185; Ms. B, fls. 315v-333.

${ }^{24}$ La de Llaguno y Amirola de 1782, nota 4.

${ }^{25}$ Kan. Es muy interesante comprobar la presencia y la herencia de los kanatos mongoles, hacía ya mucho sin mando único, que don García va situando, describiendo, y hablando de sus orígenes.

${ }^{26}$ Sah Ismā il (1487-1524), fundador de la dinastía safávida. Hijo del azerí Haydar Soltan Mirza, jeque de la tariqa Safaviyya, comunidad sufí de Ardebil, fundada por el místico Safi al-Din Ardabilí, su antepasado directo. Hoy estaríamos hablando del Conjunto del Khānegāh y del santuario del Jeque Safi Al Din en Ardebil.
} 
interior y más al sur de la Media están las ciudades de Tauris [Tabriz], Soltania [Soltaniyeh] y Casbín [Qazvín], y luego, camino de Spahan, las de Cum [Qom] y Caxem [Kashan], en los últimos confines de la Media, que contermina con la Persia.

Tauris, nobilísima, y en épocas anteriores el principal asiento de los reyes persas, está arruinada y deshabitada. Ha sido, en estos cien años, saqueada varias veces por los turcos y por eso señala que fue desamparada por el Xa Thamas y por Mahamet Codabanda ${ }^{27}$, su hijo, y también por los más ricos y principales ciudadanos, aunque todavía mostraba lo que fue antaño. Había sido tomada y saqueada por Osman Baxa pero, en 1618, cuando el embajador estaba en Casbin, Cali Baxa entró con dos ejércitos por Armenia y Media, el rey de Persia no se atrevió a ofrecer resistencia y la mandó asolar y desmantelar. Aunque en Europa se decía que Tauris antes había sido Ecbatana, don García lo desmiente, y lo justifica con textos o argumentos legibles en Luçio Lucullo, Apiano y Plutarco, entre otros. Señala que quizá Tauris fuera Susa por ser esta la capital de invierno de los primeros reyes de Persia, lo mismo que Ecbatana lo era de verano. Otra de las características de don García es su sinceridad, apunta teorías y expone sus razones, no busca establecer axiomas infundados. También un modo de trabajo.

Al sureste de Tauris, (Silva 2011: 425) a 70 leguas, está la ahora (s. XVII) arruinada ciudad de Sultania, con poco más de trescientas casas, pero con varias mezquitas que recordaban su pasada grandeza. Piensa don García (Silva 2011: 426) que aquí estaría Ecbatana, asiento y capital de la monarquía de los medos.

Continuando la costa del Mar Caspio (Silva 2011: 426), desde las bocas del río Araxes, que desde la provincia de Guilán divide a la Media occidental llamada antiguamente Atropatia, de Armenia la mayor, se entra en lo más septentrional de esta grande y memorable provincia, en otra menos y contenida en ella, que llaman los persas Siruan.

Desde Bacu (Bakú, Azerbaiyán), siguiendo la costa más o menos hacia el noroeste, dos jornadas al interior está Sumachia, cabeza del Siruan, también con importantes sederías. "La parte del Siruan, desde Sumachia y Derbento hasta el Gurgistan o Georgiania, fue antiguamente habitada por los Albanos, muy semejantes en hábito, lenguas y costumbres a los Iberos sus vecinos, que son unos y otros los georgianos de nuestros tiempos, vencidos en muchas batallas por Gneo Pompeyo y después por su legado Luçio Afranio" (Silva 2011: 429-430). A veces, como aquí, el embajador hace un recorrido geográfico, habla del clima, de lo que se produce, o de los tipos humanos que va observando, de la religión... En este punto, por ejemplo, de los distintos grupos de cristianos orientales que se encuentra.

Habla de una especie de comunidad ideal en el Gurgistán (Silva 2011: 433-4), con una comunión de costumbres y formas de vida, guardando entre ellos la caridad evangélica y compartiendo los recursos. Reconociéndoles errores en la religión, los ve más cerca de la doctrina de los Apóstoles, "que tanto falta entre nosotros". Señala que pudo estar aquí el origen de las amazonas que cantaban los griegos. Y habla luego de cómo se hizo el Xa Abbas con estas tierras. Se apoya en los antiguos para dar otros ejemplos de mujeres guerreras (Silva 2011: 436).

Un grupo de los georgianos serían los mengleros, similares en religión, costumbres y modos de vivir. Su ciudad principal es Phasso, que mantiene el nombre antiguo, situada en la desembocadura del Phasis. Reconocen señoría al Turco (Silva 2011: 436-7).

Toda la Georgina corre casi por un mismo paralelo, de occidente a oriente, desde el Mar Negro y boca del río Phasis, hasta el río Cur y provincia de Siruan. De manera que al oriente y mediodía tiene la Armenia la Mayor, cuya parte más septentrional es el Siruan, al occidente

\footnotetext{
${ }^{27}$ Sah Tahmāsp (r. 1524-1576) y Mohammad Khodabanda (r. 1578-1587).
} 
el Mar Negro, y la septentrión, aunque dividida del monte Caucaso, los lazos y çircassos. Los çircassos, que antiguamente fueron los bosphoranos y cimerios, llamados después comanos. Ve en esta zona y en este pueblo el origen de la milicia de esclavos criados desde niños en el arte de la guerra (los genízaros, por ejemplo), al servicio del califa, en distintos momentos del poder musulmán (también en la península ibérica).

Toda aquella costa del Mar Negro, desde la Mengrelia, revuelve hasta el Bosphoro Çimerio, por poniente, y después que corre hacia Levante su contracosta, bañada de la laguna de las Zabacas, o Mar de la Tana, con la tierra contenida entre ambas costas, es habitada por estos pobres çircasos, gente blanca y por la mayor parte rubia y de gentiles y robustas disposiciones (Silva 2011: 439).

Describe después la ciudad de Eruan (volviendo a Derbento y desde allí por el Siruan), ahora de Armenia la mayor, a la que Ptolomeo llamaba Terua. La señala famosa por haber revestido en 1616 un cerco de 200.000 soldados turcos, que describe. Confronta su información in situ con la de los antiguos, y su descripción, de nuevo, bien pudiera imaginarse realizada con un mapa enfrente y ampliando la información según va recorriendo el territorio.

Hay un capítulo específico para Mesopotamia ${ }^{28}$, que es un ejemplo estupendo de qué es lo que se conocía hasta los inicios del Orientalismo, a mediados del siglo XIX, sobre un período histórico que va desde el III milenio con los sumerios, hasta el 539 a.C. cuando, con la caída de Babilonia de manos de Ciro el persa, se puede entender que se cierra un periodo histórico. Antes, el conocimiento sobre el Oriente Próximo antiguo se basaba en la Biblia y en los autores clásicos, fuentes extemporáneas o que provenían de otras bases culturales.

Bajando por el Éufrates identifica Antiochia, a dos jornadas de Alepo, "sin casa en pie ni morador alguno" (Silva 2011: 444).

Sitúa después Orpha [Ourfa], que identifica con la antigua Edessa, donde se conserva la memoria del patriarca Abraham ${ }^{29}$, aunque natural de Carram, venerado por turcos y cristianos. Habla de una fuente en la Mezquita de Abraham, donde antes hubo una ermita de San Jorge. Y media legua fuera de la ciudad, sitúa otra ermita bajo la adoración de Sancto Thomas Apóstol, donde vienen cristianos armenios, jacobitas o surianos y maronitas.

Caminando desde Edesa hacia el noreste (o Griego Levante), está cruzando hacia el Tigris, se llega en seis jornadas a la ciudad de Amida (Silva 2011: 448), llamada ahora por los turcos Caramit, famosa por el sitio del rey persa Sapor en tiempos del emperador Constancio. En la actualidad esta ciudad es Diyarbakir, Turkía.

"Viniendo de Orpha a Caramit, casi a mitad de camino, lejos tres o cuatro leguas de él, y a mano derecha, está la antigua ciudad de Carras, tan conocida así por la Sagrada Escritura, llamándola Harran, como por los historiadores romanos y famosa por la muerte de Marco Crasso, y miserable Rota de su ejército" (Silva 2011: 449).

Cuatro días de camino de Caramit, al viento Les Sueste o Siroco Levante, se hayan hoy los vestigios, sin alguna duda, de la fuerte y famosa ciudad de Nisive, tantos años frontera del Imperio romano. Es un lugar grande, aunque abierto y sin muralla, con 300-400 casas, poblado de armenios y nestorianos. Unas millas más abajo, siguiendo el río, están las ruinas de Nínive, cabeza de la monarquía de los asirios, tantas veces citada en la Biblia (Jonas, Tobías, Jeremías, Sophonías y Nahun) y a menos de una legua, viéndose, está la ciudad de Mosul, poblada de jacobitas y nestorianos, con algunos turcos y árabes.

\footnotetext{
${ }^{28}$ Noticias de Mesopotamia (de Silva, 2011, p. 444). Comentarios, vol. 2, liv. 6, cap. 5, pp. 242-245; Ms. B, fls. $382-385 \mathrm{v}$.

${ }^{29}$ Abraham sería de Ur, pero su vida está muy vinculada a Harrán (Turquía).
} 
Sitúa (Silva 2011: 452) la ciudad de Seleucida ${ }^{30}$ a dos días de camino, siguiendo el Tigris al sur, en su ribera oriental. Seleucida, según Estrabón, está a 10 leguas de Babilonia, y éste es otro dato que le hace redundar en la identificación.

No sabemos cómo le contaron acerca de estas tierras, pero, al leerle, o las notas se tomaron de forma muy específica, o da la impresión de seguir con claridad un mapa. En esta parte del texto sigue el recorrido del Tigris para hacer la descripción de las ciudades y de la parte de la historia antigua clásica que habla de ella. Siguiendo, siempre, es cierto, a estos autores clásicos. Aquí a Estrabón.

Esta dependencia confesa de las fuentes clásicas se señala de muy distintas formas, también para explicar una mayor o menor extensión del texto: "Desde Birta, corre el Eufrates al Su Sueste o Siroco Medio día y después al Oriente Hiemal o Les Sueste, siendo ya término y límite, aquí, de Arabia la desierta y Mesopotamia. Y porque ansi por este río, como por ambas riberas suyas, continuaron tantas veces, los ejércitos romanos sus jornadas y empresas, contra los persas y partos, y fue por este viaje por donde mayores daños recibieron, se hará más larga relación del Eufrates que se ha hecho hasta ahora" (Silva,2011: 453).

"Desde Raba, dando el Eufrates muchas vueltas, metiéndose algunas veces por la Mesopotamia y otras por Arabia, llega hasta la ciudad de Ana, tan conocida por todos los que han hecho este viaje, o por el desierto o por el mismo río" (Silva 2011: 460). Después de describirla, con más de 1500 casas en torno a una calle, señala que, además de árabes, la habitan judíos que hablan español (¡sefardíes!).

Introduce Babilonia en su relato a partir del canal que manda construir Trajano entre el Éufrates y el Tigris, en ayuda de sus campañas en estas tierras, y tras glosar la importancia del Éufrates, hace toda una digresión, cultísima y manejando diversas fuentes clásicas, sobre la presencia romana aquí. Llega después a Bagdad (Silva 2011: 468), que describe, también a sus habitantes, y señala cómo su opulencia e incluso ellos mismos podrían provenir, o efectivamente venir, de la vecina Babilonia.

Hace otra digresión algo general, no tan detallada como en otras ciudades, en torno a Babilonia, fundamentalmente basada en la Biblia, hablando también del robo de ladrillos, o de lo que sabemos sobre la Torre de Babel y dónde pudo estar.

Si no estudiásemos el origen de nuestra ciencia, el Orientalismo, o no lo tuviésemos presente, podría sorprender los temas que trata y cuáles son sus referencias. Pese a todo, mucha información sí que nos es útil. Es curioso observar cómo en aquella época se mostraba la historia de la que fue la ciudad más importante del mundo, y cómo, sin embargo, lo que se mostraba era el horno donde metieron a Daniel, el lago o cisterna de los leones o dónde se realizó el juicio y salvación de Susana a quien quisiera escucharlo. Hoy, a veces, seguimos engañando a los turistas o enseñándoles lo que quieren ver, sea verdad o no. No debería extrañarnos tanto aquellas visitas o lo que se decía de la ciudad.

Babilonia se conocía por la Biblia, y era eso lo que se buscaba. Por ejemplo, la búsqueda de la torre de Babel es una constante, que también realiza nuestro viajero, aunque hoy sabemos que no se podría encontrar, pues fue desmantelada por Alejandro para reconstruirla, pero esta segunda fase no se llevó a realizar. Solo con el trabajo de Koldewey ${ }^{31}$ se pudo constatar tal circunstancia.

Es muy interesante la descripción del espacio que lleva a cabo, de las ruinas, aún magníficas cuando él las visita, la extracción continua de ladrillos que señala varias veces en su texto, o la presencia de los canales que permitieron florecer la agricultura y por lo tanto

\footnotetext{
${ }^{30}$ Seleucia. Al otro lado del Tigris estaba Ctesifonte.

${ }^{31}$ Koldeway 1913: passim.
} 
la civilización mesopotámica. Don García busca describir y contrastar, con las fuentes de conocimiento que le son válidas. "De su grandeza, y admirable fortaleza de sus muros, con las demás fábricas milagrosas suyas, hay tan particular y general noticia en todos los autores más graves de la antigüedad, que de ellos se ha traspasado, y derivado, hasta las más remotas partes de Europa" (Silva 2011: 473). Estas son sus fuentes y el público objetivo. Habrán de pasar más de tres siglos para que otros europeos empiecen a desenterrar y descifrar aquel pasado que está en el origen de nuestra civilización. Para Europa, su recuerdo estaba en la Biblia y en los clásicos. La memoria de su grandeza, y el orgullo de la misma, no se perdió nunca in situ.

Describe después, tras narrar cómo Alejandro Magno, según Diodoro Sículo, estuvo tres días perdido por las lagunas del Éufrates poco antes de morir, el Shatt al Arab, la unión del Éufrates y del Tigris antes de Basora (Silva 2011: 478), para desembocar así en el Mar Pérsico. Desde Bagdad a Basora son ocho o nueve días con la corriente a favor, pero treinta o cuarenta remontándolo, y saliendo siempre a dormir a tierra.

No entiende que, siendo su Majestad Católica señor de Ormuz, no controle todo el "Seno Persico", y lo achaca a que los gobernadores portugueses, que cada tres años se renuevan, entienden su puesto solo como un medio para enriquecerse.

Describe después la isla de Bahrein, y habla de la fortaleza que tienen los persas en ella, aunque veinte años antes pertenecían al señor de Ormuz.

Acaba esta larga descripción de la geografía no visitada de Persia hablando de la provincia de Susien o Sophien, que es la famosa Susiana antigua (Silva 2011: 484), tan célebre en la Antigüedad, por el asiento y corte de los poderosos reyes de Persia, señores de toda Asia.

El trabajo de don García fue costoso, doliente de mil trabas, seguramente pasado ya el momento de conseguir la alianza pretendida, y con dificultades a un lado y al otro de donde él se desempeñaba. Pero de este trabajo queda un resultado magnífico, sus Comentarios, que en esta contribución nos sirven para estudiar cómo mostraba la geografía del país a quienes le leyesen, y cómo describía la geografía con palabras que se pudieron apoyar en mapas, o servir para la constitución de uno que bien hubiese podido estar previsto o construyéndose.

\section{Conclusiones}

El trabajo de don García sorprende desde distintos puntos de vista, constituye una importante fuente de referencia sobre el viaje, la geografía, historia y realidad contemporánea del país que visita, pero solo desde hace poco lo podemos estudiar o ha sido tenido en cuenta de forma relevante dentro del Orientalismo. Cuando analizamos las embajadas que se dieron entre Europa y el sah Abbas de Persia solemos obviar, por desconocimiento, uno de los testimonios más importantes, que estaba en comunicación con la corte hispana mientras estaba destacado en la corte persa. Muchos de los problemas y las intrigas que se analizan en otros textos y documentos serían muy interesantes de contrastar con los Comentarios que venimos estudiando.

El embajador era un humanista que viajaba con su biblioteca, y analizaba esas fuentes y otras contemporáneas para describir y analizar el territorio que iba recorriendo. En función de todas estas fuentes identificó Persépolis que además ubicó de forma exacta, y señaló que el cuneiforme era una forma de escritura, y no meros dibujos, seguramente por primera vez en época moderna. Trajo testimonios gráficos de la ciudad persa y de la escritura que allí se ubicaba, pero no se conocieron hasta mucho después, siendo, sin embargo, otros testimonios menos relevantes o posteriores los que se cuentan entre los pioneros del Orientalismo. Describió y ubicó los grandes restos arqueológicos de la zona, tratando de comprenderlos con 
la información que tenía. Cuando surgió el Orientalismo, la historia que se descubrió hubo de ser desenterrada y descifrada, llevaba dos milenios bajo la tierra, y su recuerdo provenía de fuentes externas, temporal y culturalmente.

En este artículo hemos tratado de trazar un dibujo de otras descripciones, textuales y cartográficas, de Persia, que eran contemporáneas a los Comentarios de don García. No hay un mapa de lo que está describiendo y, sin embargo, a veces parece que es eso lo que está narrando o se está apoyando en uno. Contrastar este texto que aquí planteamos, que a veces pretende emular al de don García, o le cita directamente, con un mapa contemporáneo, así lo demuestra.

En esta contribución, además de ubicar el texto en su contexto cultural, o presentar someramente al embajador o la historia del libro, hemos seguido una parte de la descripción que hace de la parte del país que no ha visitado. La riqueza del detalle, la contextualización histórica y la claridad del texto, animan a continuar trabajando e indagando en los Comentarios de don García de Silva y Figueroa, queda todavía mucho por investigar.

\section{Bibliografía}

Biedermann, Z., 2011, "Um viajante sem mapas? Figueroa e a cartografia da Pérsia", in R. M. Loureiro \& V. Resende (coords.), Estudos sobre Don García de Silva y Figueroa e os "Comentarios" da embaixada à Pérsia (1614-1624), Volume 4, Centro de História de Além-Mar, Lisboa, pp. 367-393.

Brancaforte, E. C., 2011, "The Encounter between Pietro della Valle and García de Silva y Figueroa at the Safavid Court of Shah 'Abbas I", in R. M. Loureiro \& V. Resende (coords.), Estudos sobre Don García de Silva y Figueroa e os "Comentarios" da embaixada à Pérsia (1614-1624), Volume 4, Centro de História de Além-Mar. Lisboa, pp. 395-409.

Colón, Fernando o Hernando, 1850, "Discurso declaratorio del derecho que la corona tiene en la conquista de Persia", in M. Salvá y P. Sainz de Baranda (eds.), Colección de documentos inéditos para la historia de España XVI, Madrid, pp. 382-420.

Córdoba Zoilo, J. M. (ed.), 2005, Arbor, no 711-712, Españoles en Oriente Próximo (11661926), Aventureros y peregrinos, militares, cientificos y diplomáticos olvidados en el redescubrimiento de un mundo, Madrid.

Córdoba Zoilo, J. M., 2006, "Don García de Silva y Figueroa, y el redescubrimiento de Irán”, in J. M. Córdoba Zoilo y M. C. Pérez Díe (coords.), La aventura española en Oriente (1166-2006), Viajeros, museos y estudiosos en la historia del redescubrimiento del Oriente Próximo Antiguo, Madrid, pp. 89-98.

Córdoba Zoilo, J. M., 2016, "Viaje, hallazgos y fortuna de dos viajeros europeos del siglo XVII en Irán: García de Silva y Pietro del Valle", Isimu 15. Recuperado a partir de https://revistas.uam.es/ isimu/article/view/3328

Córdoba Zoilo, J.M. y Pérez Díe, M.C., 2006, La aventura española en Oriente (1166-2006). Viajeros, museos y estudiosos en la historia del redescubrimiento del Oriente Próximo antiguo. Madrid.

Chardin, J., 1686, Voyages de Monsieur le Chevalier Chardin en Perse et autres lieux de' L'Orient, $1^{\text {a }}$ parte. Amsterdan.

Escribano Martín, F., 2017-18, "Consecuencias bibliófilas de las embajadas entre España e Irán en el siglo XVI”, Isimu 20-21, pp. 87-103. 
Fernández de Figueroa, M., 1512, 1999, Conquista de las Indias de Persia e Arabia que fizo la armada del rey don Manuel de Portugal e de las muchas tierras, diversas gentes, extrañas riquezas y grandes batallas que allá hubo. En sumario del bachiller Juan Agüero de Trasmiera. Introducción, edición crítica y notas de L. Gil Fernández. Universidad de Valladolid.

Gil Fernández, L., 2006 y 2009, El Imperio luso-español y la Persia safávida. Tomo I (15821605) y Tomo II (1606-1622). Madrid.

Gil Fernández, L., 2018, De pirata inglés a repúblico español. Vida e industrias de Antonio Sherley (1565-1633). Madrid.

Gouvea, Antonio de, 1609, Jornada do Arcebispo de Goa Dom Frey Aleixo de Meneses Primaz da India Oriental Religioso da Ordem de S. Agostinho. Quando foy as Serras de Malawar \& lugares en que morão os antigos Christãos de $S$. Thome, \& os tirou de muytos erros, \& heresias em que estavão, \& reduziu a nossa Fe Catholica \& obediencia de Santa Igreja romana da qual passava de mil annos que estavão apartados, recopilada de diversos tratados de pessoas de autoridade que a tudo foram presentes, por Frey Antonio Gouvea, Coimbra, 1606; tr. F. J. de Glen as Histoire Oriental des grans progrès de l'Eglise Cath. Apost. et Rom. En la Réduction des anciens Chrestiens, dits de S. Thomas, de plusieurs autres Squismatiques et Hérétiques à l'Union de la vraye Elgise: conversion encore des Mahométanes, Mores \& Payens, pas les bons devoirs de Rome \& illustre Sr. Don Alexis de Ménèsès, de l'Ordre des Ermites de S. Augustin, Archeveque de Goa et Primat en tout Orient. Brussels.

Gouvea, Antonio de, 1646, Relaçam em que se tratam as guerras e grandes vitórias que alcançou o grande Rey de Persia Xá Abbas, do grão Turco Mahometo, e seu filho Amethe as quaes resultarão das Embaxadas que por mandado da Catholica Real Majestade de Rey D. Felippe II de Portugal fizerão alguns Religiosas da Ordem dos Ermitas de Santo Agostinho à Persia, Lisbon, 1611; tr. A. de Meneses as Relation des grandes guerres et victoires obtenues par le roy de Perse Cha Abbas contre les empereurs de Turquie Mahomet et Achmet son fils, ensuite du voyage de quelques religieux de l'ordre des Hermites de Saint-Augustin envoyés en Perse par le Roy catholique Don Philippe second roy de Portugal. Rouen.

Herbert, T., 1634, A relation of some yeares trauaile begunne anno 1626. Into Afrique and the greater Asia, especially the territories of the Persian monarchie: and some parts of the orientall Indies, and iles adiacent. Of their religion, language, habit, discent, ceremonies, and other matters concerning them. Together with the proceedings and death of the three late ambassadours: Sir D.C. Sir R.S. and the Persian Nogdi-Beg: as also the two great monarchs, the King of Persia, and the Great Mogol. By T.H. Esquier. London, Printed by William Stansby, and Iacob Bloome.

Invernizzi, A., 2011, "Pietro della Valle a Persepoli e il suo incontro con García de Silva y Figueroa”, in C. Masetti (ed.), De’Viaggi di Pietro della Valle Il Pellegrino, Roma, Societá Geografica Italiana, pp. 37-50.

Koldeway 1913: passim.

Lambert, C. \& Morisot, C.-B., 1651, Trois relations d'Aegypte, et autres memoires curieux des singularitez dudit pays. Relation d'un voyage de Perse fait és anneés 1598 \& 1599. Paris, Augustin Courbé.

Marías, F., 2002, "Don García de Silva y Figueroa y la percepción del Oriente: la "Descripción de Goa"”, Annuario del Dpto. de $H^{a} y T^{a}$ del Arte (UAM), XIV, pp. 137-149.

Masó Ferrer, F., "Don García de Silva y Figueroa. El diplomático que descubrió Persépolis, recuperado del Boletín en red de la Sociedad Geográfica Española" (recuperado el 19/08/2020): https:// sge.org/exploraciones-y-expediciones/galeria-de-exploradores/la-vuelta-al-mundo/embajadaspersia-garcia-silva-figueroa-1616/ 
Matthee, R., 2012, "Safavid Iran through the Eyes of European Travelers", in W.P. Stoneman (ed.), From Rhubard to Rubiefs: European Travels to Safavid Iran (1550-1700), The Lands of the Sophi: Iran in Early Modern European Maps (1550-1700), Harvard Library Bulletin 23, pp. 10-24.

Membré, M., 1542, 1969, Relazione di Persia: Ms. Inedito dell'Archivio di Stato di Venezia, G. R. Cardona y F. Castro (eds.). Venezia, Istituto Universitario Orientale.

Membré, M., 1999, Mission to the Lord Sophy of Persia (1539-1542). Translated with Introduction and Notes by A.H. Morton. Warminster, Gibb Memorial Trust.

Olearius, A., 1647, Offt begehrte Beschreibung Der Newen Orientalischen Reise / So durch Gelegenheit einer Holsteinischen Legation an den König in Persien geschehen: Worinnen Derer Orter und Länder/ durch welche die Reise gangen / als fürnemblich Rußland / Tartarien und Persien / sampt ihrer Einwohner Natur/ Leben und Wesen fleissig beschrieben / und mit vielen Kupfferstücken / so nach dem Leben gestellet / gezieret / Durch M. Adamum Olearium, Ascanium Saxonem, Fürstl: Schleßwig-Holsteinischen Hoff-mathemat. Item Ein Schreiben des WolEdeln [et] c. Johann Albrecht Von Mandelslo: worinnen dessen OstIndianische Reise über den Oceanum enthalten; Zusampt eines kurtzen Berichts von jetzigem Zustand des eussersten Orientalischen KönigReiches Tzina. Schleswig.

Polczynski, M., 2014, The Relacyja of Sefer Muratowicz: 1601-1602 private royal envoy of Segismund III Vasa to Shah 'Abbas I. Turkish Historical Review, Georgetown University.

Sherley, A., 1613, Sir Anthony Sherley: his Relation of his Travels into Persia. El manuscrito original está en la Biblioteca Bodleian de Oxford.

Silva y Figueroa, García de, 1624, Comentarios de don García de Silva que contienen su viaje a la India y de ella a Persia, cosas notables que vió en él y los sucesos de la embajada al Sophi. [Manuscrito]

Silva y Figueroa, García de, 1903 y 1905, Comentarios de Don García de Silva y Figueroa de la Embajada que de parte del Rey de España don Felipe III hizo al rey Xa Abas de Persia. Edición de Manuel Serrano y Sanz. Madrid, Sociedad de Bibliófilos Españoles.

Silva y Figueroa, García de, 2011, Comentarios de la Embaxada al Rey Xa Abbas de Persia (1614-1624). Edición de Loureiro, R.M., Costa Gomes, A.C. y Resende, V., en dos tomos, junto a otros dos tomos de anotaciones y estudios. Lisboa, Centro de História de Além-Mar, Universidade Nova de Lisboa y Universidade dos Açores.

Stodart, R., 1935, The journal of Robert Stodart: being an account of his experiences as a member of Sir Dodmore Cotton's mission in Persia in 1628-29. Published from the unique manuscript preserved in the Bodleian library / with an introduction and notes by Sir E. Denison Ross. London, Luzac \& co.

Tavernier, J. B., 1676, Les six voyages de Jean Baptiste Tavernier, écuyer baron d'Aubonne, en Turquie, en Perse, et aux Indes, pendant l'espace de quarante ans, \& par toutes les routes que l'on peut tenir: accompagnez d'observations particulieres sur la qualité, la religion, le gouvernement, les coûtumes \& le commerce de chaque païs, avec les figures, le poids, \& la valeur des monnoyes qui y ont cours. París, Gervais Clousier.

Thévenot, J., 1665, Relation d'un voyage fait au Levant dans laquelle il est curieusement traité des Estats sujets au Grand Seigneur... Et des singularitez particulieres de l'Archipel, Constantinople, Terre-Sainte, Egypte, Pyramides, Mumies ["sic"], Deserts d'Arabie, la Mèque. Et de plusieurs autres lieux de l'Asie \& de l'Affrique,... Outre les choses memorables arrivées au dernier Siege de Bagdat, 
les Ceremonies faites aux receptions des Ambassadeurs du Mogol: Et l'entretien de l'Autheur avec celuy du Pretejan, où il est parlé des sources du Nil. Par Monsieur Thevenot. París, Rouen, Louis Billaine.

Turyley, J.S. \& Souza, G. B., 2017, The Commentaries of D. García de Silva Y Figueroa on His Embassy to Shāh 'abbās I of Persia on Behalf of Philip III, King of Spain. Leiden.

Uruch beig Bayyat / Juan de Persia, 1604, Relaciones de Don Ivan de Persia. Dirigidas a la Magestad Catholica de Don Philippe III. Rey de las Espurias, y señor nuestro. Divididas en tres libros, donde se tratan las cosas notables de Persia, la genealogía de sus Reyes, guerras de Persianos, Turcos y Tartaros, y las que vido en el viaje que hizo a España: y su conuersion, y la de otros dos Caualleros Persianos. Año 1604. Con privilegio, Valladolid, por Iuan de Bostillo: en la calle de Samano.

Uruch beig Bayyat / Juan de Persia, 1946, Relaciones de don Juan de Persia, prólogo y notas de Narciso Alonso Cortés. Madrid.

Varthema, Ludovico de, 1510, Itinerario de Ludovico de Varthema bolognese ne lo Egypto, ne la Suria, ne la Arabia deserta \& felice, ne la Persia, ne la India, \& ne la Ethiopia. La fede el viuere \& costumi de le prefate provincie. Et al presente agiontoui alchune isole novamente ritrovatte. Roma. 